\title{
THE PRESENT POSITION OF EXPERIMENTAL CANCER RESEARCH
}

\author{
By P. T. J. C. P. Warner, M.D., Ph.D. \\ From the Bland-Sutton Institute of Pathology, The Middlesex Hospital
}

The volume of literature concerning cancer research is vast. In order to be certain of not missing anything having direct reference to it, 60 journals and annual publications would have to be examined. This article is not intended to be a comprehensive survey of the subject but is an attempt to show to what extent the findings in the main branches of experimental cancer research shed light on the cause of cancer.

Cancer research as a whole may be divided into two parts, the first being the clinico-pathological aspect which comprises the study of the treatment and incidence of cancer in human patients; the other part is experimental cancer research which consists largely of experiments on animals, and draws on the wider field of the basic sciences.

Experimental cancer research (' cancer' in this context includes neoplasms which are benign or malignant, carcinomata or sarcomata) began with the discovery of neoplasms in animals. It was found that pieces of such neoplasms, when implanted into an animal of the same species, would grow in the new host. Neoplastic cells remained viable, gained nutriment from the new host and continued to grow. Such transplantable tumours are the basic tool of the greater number of experimental workers in this field and have had an immense amount of study expended upon them. The behaviour of some of them are so well known that they are used as standard tumours upon which, nowadays, the effect of chemotherapeutic agents and dietetic factors are tried with a view to applying them to the human subject. This appears, at first sight, to be convenient and suggests that this method would provide results as clear cut as have been obtained with, for instance, penicillin and sulphonamides with bacteria. However, this has not been found to be the case. So many factors have revealed themselves which govern tumour growth that results are not always what they seem. For instance, a chemical substance may be administered to mice which have tumours growing on them and it may be found that as the result of treatment the tumours disappear, whereas those in a control series do not. At once the discoverer of such a phenomenon is of the opinion that the chemical is specifically anti-cancer, but more careful work shows that the same result may be obtained by starving the animals or by depriving them of particular constituents of their tood.

Many substances have been tested for their anti-cancer properties and although many have appeared promising there is not one which has so far stood the test of time and careful evaluation. The same thing may be said of the various tests for cancer which have appeared from time to time; there is no known test, other than combined clinical and histological examination, which will detect cancer in an animal or a human being.

The remainder of the bulk of experimental cancer research may be divided into two, the investigation of the part played by viruses in cancer and the study of the production of neoplasms with chemical agents.

\section{Viruses and Cancer}

After the discovery of the transplantable tumour it was found that some tumours could be transmitted from one animal to another by means of saline suspension from which all cells had been removed by means of filtration. The active agent in the saline suspensions was found to have the properties of a virus. The essential properties of viruses are:-

I. They are small particles ranging in size from that of a protein molecule to something less than the smallest bacterium.

2. They can be separated from cells which are infected by them and on inoculation into a new host of the same species will produce similar effects therein.

3. They will only multiply in number in the presence of living cells.

Numerous chicken tumours, two in rabbits, one in frogs and some mammary carcinomata in mice have been described which can be transmitted by viruses.

The most famous example of the virus tumours of chickens is the Rous sarcoma. The Rous virus has the property of producing serum antibodies. It has been found that some transplantable chicken tumours which are not known to be transmitted by viruses possess an antigen in common with the 
Rous and other chicken tumour viruses. Also, on rare occasions it has been found that injections of tar will produce tumours in chickens which have subsequently been transmissible by viruses. These two findings gave rise to the theory that all tumours were caused by viruses which lay latent in the tissues until activated by some unknown agent or carcinogenic chemical such as tar.

Of the rabbit virus tumours, the Shope papilloma is best known. This is a benign growth, but occasionally in wild rabbits it becomes malignant. No virus has been separated from the malignant growth in adult rabbits, but rabbits which bear it develop serum antibodies which neutralize the Shope virus. Thus, it was said that the virus was present in the malignant growth in a masked form. However, one strain of this malignant growth after several years lost its property of inducing antivirus antibodies in the sera of rabbits in which it was growing-this suggested that although the virus was present originally it was not essential for the continuation of the new growth. It has been possible to transplant the carcinoma derived from the Shope papilloma into suckling rabbits and it has been reported that a virus has been separated from this growth. This virus, however, did not produce cancers but papillomata on inoculation. There are no end to the explanations which could be applied to these findings. However, all it is possible to say with assurance is that the virus, although usually present in some form or other in the carcinoma, is not essential for the continued abnormal cellular division and even when separated from it will not give rise to another cancer.

In the early stages of experimental work on the mammary adenocarcinomata of mice it was thought that this disease was determined by heredity for the simple reason that some families or strains of mice had a high incidence of this disease, whereas others did not. However, the observed facts did not fit accurately into the framework of the laws of Mendelian heredity. The next stage in this work consisted of some cross-mating experiments carried out over a number of year:, which resulted in the finding that predisposition to mammary carcinoma in mice was transmitted by the female parent alone and therefore there must be some factor other than a hereditary one which governed the transmission of this disease; in fact, there must be something outside the chromosomes which is responsible for it-this has been christened the 'extrachromosomal factor.'

Three years later, Bittner, using two strains of mice, a low cancer and a high cancer strain, removed the young within 24 hours of birth. $\mathrm{He}$ allowed the young of the low cancer strain mothers to be suckled by mothers of the high cancer. strain and vice versa. The result was that those mice which had been suckled by the high cancer $\frac{1}{2}$ strain developed a high incidence of breast cancer, $\stackrel{\complement}{c}$ whereas those which had been suckled by a low cancer strain had a low incidence. In short, irrespective of their genetic constitution, the inci-o dence of breast cancer in either group of mice $\underline{\overline{\bar{\sigma}}}$. was of the same order as the incidence of the $\frac{\bar{\Phi}}{\vec{D}}$ disease in the mice from which they obtained $\stackrel{\otimes}{\circledR}$ milk. Thus, the extrachromosomal factor referred to above was present in the maternal milk and $\vec{\circ}$ was named the ' milk factor.'

After the discovery of the milk factor it was $\vec{\omega}$ shown that not all strains of mice were equally sensitive to its influence. In fact, susceptibilityo to the milk factor was determined by heredity Thus, heredity plays a part in the development of N $^{\circ}$ breast cancer in mice but not in the way that was $\omega$ originally thought.

Some strains of virgin mice and spayed mice which i had received the milk factor from their motherso were found to have a much lower incidence of $\rightarrow$ breast cancer than breeding mice from the samec strain, unless oestrogens were administered when the cancer incidence approached that of the breed-⿳亠丷厂 ing mice. This showed that oestrogenic stimula-tion of breast tissue favoured a high incidence off $\vec{c}$ cancer.

The milk factor is a particulate virus. It can deposited by centrifugation and can be transmitted by cell-free filtrates and, it is claimed, will induce $\frac{\bar{O}}{0}$ serum antibodies. Particles associated with breast tissue from high cancer but not low cancer strains $\stackrel{\Omega}{\mathbb{D}}$ in mice have been demonstrated in the electron $\overrightarrow{\vec{P}}$ microscope.

The milk factor virus is different from those causing the fowl tumours and the Shope papil-o. loma. It has a long incubation period of many months. Its effect is specially localized in the 3 . mammary gland. It does not produce its effect at: the site of inoculation; it is spread by ingestion of maternal milk. Its effect is dependent on anô adequate supply of hormones-oestrogens in particular. However, although some of the pro-윽 perties of the milk factor virus differ from those $>$ of the other carcinogenic viruses they do not differ from the properties of certain other viruses, $\bar{N}$ therefore there can be no objection to calling the milk factor a virus. There does, of course, $\mathbb{N}$ remain some doubt as to how the virus causes thew disease-does it in fact enter the cells of the mammary gland, multiply therein and therebyo produce the disease or does it, in some way, alterథ the structure of hormones affecting the breast ${ }^{?}$ or the hormone balance thus causing mammary adenocarcinoma? The question is part of a much? wider one: how do viruses produce their recog-邑 nizable effects? Are they necessarily always $\stackrel{\mathbb{Q}}{\Omega}$ 
present within the cells which show the particular effects which have become known to be associated with a particular virus? It is possible that viruses produce their effects on cells at a distance, as may be the case with the milk factor. It has been suggested that the milk factor virus in some way alters hormones which are then able to produce mammary adenocarcinomata (Bittner, I948; Pullinger, 1949). This mode of action is not likely to be that of the Rous sarcoma virus or the Shope papilloma virus which produce their effects locally at the site of inoculation. It is likely that these viruses actually infect the cells which show the pathological effect specific to the virus in question. However, whether the virus is within the cell or outside it, its effects appear within the cell, and it is the tumour cells which must be studied.

It is not clear whether the continued action of virus is necessary for the neoplastic nature of each . cell and its descendants or whether the virus alters the genetic constitution of the first cell that it affects so that all daughter cells, irrespective of the action of virus, will be neoplastic. In short, the crucial question is: if tumour-virus were destroyed would the affected cells return to normal or not? At present one cannot determine the answer to this question, for, on the one hand, it is usual to find virus at all times in those tumours which have been initiated by virus; on the other hand, it could be said that such a virus had done its initial damage to the cells of the tumour and continued multiplying within those cells merely as a passenger or symbiont. Furthermore, one strain of Shope carcinoma in which, at first, there was indirect evidence of the persistence of virus bound within the cells, later failed to show evidence of virus but still retained its neoplastic character. Plainly in this particular case the presence of virus was unnecessary for the continued neoplastic character of the cells. We do not know, however, what has happened to a virus which originally could be separated from a papilloma, could be detected in a carcinoma derived from the papilloma and which finally disappeared from the carcinoma.

In order to explain these problems it is necessary to go back to first principles. It is in this way only that the rôle of virus in neoplasia can be clearly assessed. We prefer to state the following hypothesis: all neoplasms are caused by intracellular biologically active particles. Some of these can be separated from cells and may rightly be called viruses. Others are more or less closely bound with cell protoplasm and do not necessarily merit the name 'virus.' The arguments which lead up to this statement are as follows:-

Whatever may initiate a neoplastic process, be it virus or chemical carcinogen or altered hormone $\frac{a}{2}$ or organizer (Needham, I942), the cause of the continuation of that process resides within the $c$ neoplastic cell. This is shown by the fact that when neoplastic cells are transplanted from one $\stackrel{\mathscr{S}}{\stackrel{9}{+}}$ animal to another they retain their neoplastic characteristics. Now, this continuing cause could either be the presence of an abnormal agent or the lack of a normal constituent within the cell. $\Omega$ Whichever it is, its size is small otherwise its presence or absence could be detected by the light microscope. There is no evidence that it is a simple chemical compound, and thus it is complex and has the size of one or more complex molecules. Therefore, we can say with some assurance that the continuing cause of neoplastic growth is the presence or absence of an entity which is chemically complex and of the same $\dot{\omega}$ order of size as viruses or protein molecules. $\vec{v}$ These we will call, non-specifically, 'particles.' N

'To turn to neoplasms themselves, of these 을 there are all kinds: the ' normal neoplasm' (the foetus), monsters, teratomata, and the other ${ }^{2}$ tumours, benign and malignant, carcinomata and sarcomata. Although typical examples of each of these can be recognized there are intermediate types giving a whole range or spectrum of neof plasms from the foetus to cancers. In the foetus. at one end of the scale the nature of cell division is governed, in part certainly, by genes. At the other end of the scale there is reason to believe that viruses are responsible for the nature of cell division. In between these extremes there are those tumours in which there is indirect evidence of the presence of virus bound to cell protoplasm, for instance: one strain of Shope carcinoma and certain chicken tumours. Thus, the particles responsible for neoplastic growth range from genes, integral parts of the cell, through the virusprotoplasm complexes, not separable from the cell but detectable as abnormal within it, to viruses proper which can be separated from cells. Into this scheme we can fit those postulated particles responsible for tumours of which the 9 continuing cause is undiscovered. These particles could be integral parts of the normal cell which have become abnormal: genes, for instance, or $\stackrel{N}{\sigma}$ some constituent of the cytoplasm-such as plasmagenes (Darlington, I 944, I948). Such 0 particles could have been rendered abnormal by $\omega$ carcinogenic agents or altered hormones or some $\bar{q}$ unknown factor. With these facts in mind it is 0 now possible to make a rough classification of all neoplasms according to their intracellular par-? ticulate continuing cause. This is shown in Table I.

If after this it is assumed that some of the particles, described above, can vary from time to 
time in the strength of union they have with cell protoplasm (shown by arrows in Table I), then certain outstanding facts can be explained. It explains how tar-induced and similar tumours could have yielded a virus by rendering abnormal a cell particle which subsequently became separable from the cell and acquired the property of invading other cells and multjplying therein. It explains how 'virus' can be detected in nonfilterable chicken tumours by serological methods. It explains how the Shope papilloma yields a separable virus whereas, in a carcinoma derived from it, a 'virus' is only indirectly detected and it explains how the 'virus,' inseparable from the carcinoma, could become so completely identified with cell protoplasm that it is no longer detectable even by indirect means. The fact that another strain of Shope carcinoma, when grown in suckling rabbits, yields a virus capable of producing papillomata is not at variance with this hypothesis.

In the foregoing it will be seen that the term ' virus' is placed between inverted commasthis is done on those occasions where the so-called virus' is inseparable from cell protoplasm. Where this occurs the so-called 'virus' does not have one of the fundamental properties of viruses according to the definition stated earlier in this article. This is a very important point to appreciate for it has led to a great deal of confusion and may, as we shall see, lead to more in the future.

The hypothesis outlined here embraces all the problems which confront the experimental cancer research worker, it rejects none of the existing evidence. There is further support for the hypothesis: Claude (1938) isolated a fraction from normal chick embryo tissue which resembled the Rous sarcoma virus in size and chemical and some physical properties. Electron microscopy has shown particles in cells of the Rous sarcoma (Claude and Porter, 1947) and in those of the milk factor tumours (Porter and Thompson, I948) and associated with human cancers (Gessler and Grey, I947; Gross, Gessler and McCarty, 1950). Serologically specific particles of the same order of size of viruses have been demonstrated in the Brown-Pearce rabbit carcinoma (Kidd, I946). Darlington ( 1948 ) originally suggested a method of approach to cancer somewhat similar to that described here; he provides evidence from other branches of biology which support it by analogy. Bauer (1949) showed that viruses might originate as constituents of cells which become abnormal, split off from their parent cell and require the property of invąding and multiplying within other similar cells. After which they could be passed from individual to individual and become the infectious viruses as they are known today. It must be pointed out here that this view of the origin of viruses is not shared by Burnet (1945). 'The postulated stages of development of viruses are indicated by arrows in Table $I$ and are placed above the classification of neoplasms.

Having reached this point, it is well to consider the value of the hypothesis outlined here. Firstly, it gives direction to experimental work. Attention can be directed to defining the particles in cells which cause neoplasia by using such methods as separation of particulate cellular components by, for instance, centrifugation, by serological, histochemical and electron microscopical methods. Secondly, the rôle of virus in neoplasia can be clearly considered: viruses are small particles which will multiply in living cells only; these are the properties, about which everyone agrees, peculiar to viruses alone. If, in addition, viruses are assumed to be particles which can, without losing their biological activity, be separated from cells in methods in use today, then, obviously, viruses are the cause of some but not all neoplasms. If, on the other hand, the term ' virus' is assumed to cover any particle which may in the future be separated from cells by newly discovered techniques, without losing their biological activity, then the situation becomes confused and may even be reduced to absurdity, for example: viable genes may in the future be separated from cells: be introduced into other cells, alter them and divide within them. If we accept the seconct assumption made above, then it would be legitimate to call genes ' viruses,' which is undesirable and confusing. In short, whether or no neoplasms are caused by viruses, will depend on the precise definition of the term 'virus.' Bearing this in mind it can be seen that all those whose theory it is that all neoplasms are caused by viruses are on safe ground. However, such a theory is unnecessary. 'The following hypothesis, stated above, is sufficient: all neoplasms are caused by intracellular biologically active particles. Some of these can be separated from cells and may rightly be called viruses. Others are more or less closely bound with cell protoplasm. Investigation should be directed to defining such particles and determining their properties. Only after this will it be profitable to decide whether to call them virus, provirus, plasmagene or any other name that has been or is likely to be considered.

\section{The Production of Neoplasms by Chemical Substances (Chemical Carcinogenesis)}

The study of chemical carcinogenesis arose from Percivall Pott's (I775) observation that chimney sweeps were prone to carcinoma of the scrotum which he ascribed to the prolonged and continuous irritation of scrotal skin by soot. Similar and often quoted examples of cancer following chronic 
irritation included the 'industrial cancers,' such as mule spinners' cancer, shale oil workers' cancer and those cancers caused by the irritation of aniline dyes, paraffin and tar (Oberling, 1944). This branch of study was put on an experimental footing when Yamagiwa and Ichikawa (1915, r9r8) induced tumours on the skins of rabbits and mice by painting them with tar. From this piece of work developed the whole study of chemical carcinogens. The next stage was when Kennaway in 1921 began to try and isolate from tar pure chemicals responsible for producing cancer. First, it was demonstrated that compounds containing only carbon and hydrogen could be carcinogenic. Next, such chemicals were shown to have emission spectra of the same type as the polycyclic hydrocarbons. This was followed by the synthesis of several polycyclic hydrocarbons, some of which were shown to have carcinogenic activity. Finally, in 1933, one of Kennaway's team isolated a pure polycyclic hydrocarbon from tar which would also produce neoplasms. This brilliant work of Kennaway and his team has opened out a wide field of cancer research in which chemicals of all kinds of known constitution have been tested for carcinogenic activity. For instance, the similarity between the chemical configuration of known carcinogens and that of oestrogens has led to the trial of oestrogenic hormones, which have been found in massive doses to produce mammary cancers in mice. However, it was found later that the chemical configuration itself was not responsible for the carcinogenic properties because similar cancers were produced by synthetic oestrogens. During these studies it has been found that certain chemicals, not themselves carcinogenic, had the effect of potentiating the effects of carcinogens and some had the reverse effect-even some carcinogenic chemicals were shown to have an inhibitory effect on the growth of tumours in animals. The mechanism of these inhibitory and potentiating effects of chemicals have been very carefully studied but nothing concrete has arisen from such studies yet.

An immense amount of work has been carried out on chemical carcinogenesis and it has now reached a point of refinement where the structure of chemical carcinogens is being related to that of the component parts of the cell. In fact the work on chemical carcinogenesis and that on virus in neoplasia are converging on a study of the cell itself and its components. It is obvious that chemical carcinogens must alter a part of the cell so that the descendants of that cell divide in a neoplastic way long after the carcinogen is no longer present. This is stating the situation in its simplest fashion and it is not necessary for the understanding of it to do more. However, the carcinogenic chemical may affect the genes, in which case a mutation may be said to have occurred. Recently particles have been discovered in paramecia which are outside the nucleus and which govern hereditary characteristics-these can be passed from one organism to another during life. They are called plasmagenes (which it will be noted have some of the fundamental properties of a virus). There may be other such extranuclear particles which can be altered by carcinogenic chemicals. It may be possible to detect such altered particles by serological means or they may become detached from the cell and when introduced to other cells of the same kind produce the same changes in it and thus giving rise to carcinogenic viruses proper. In fact, experimental cancer research has left one in the realm of speculation, but the speculation described here has not outgrown its strength. It leads to a study of the particulate components of the normal and neoplastic cell and any research which provides more knowledge about them advances the solution of the problem of cancer and perhaps that of living matter.

What then is the present position of experimental cancer research ? There are two current theories as to the causation of cancer. The first states that all cancers are caused by viruses, and the second that cancer is abnormal cell proliferation governed by a mutation. If we accept, as we must, the definition of viruses as given above then we know that some cancers are caused by viruses and that others are not. It may be that the carcinogenic viruses produce mutations in the cells which they invade-also it may be that carcinogenic chemicals can produce viruses from living cells. It is clear now that the two current theories are neither contradictory nor mutually exclusive and both are to some extent true.

\section{BIBLIOGRAPHY}

BAUER, D. J. (1949), Nature, 164, 767.

BITTNER, J. J. (1948), Cancer Research, 8, 625.

BURNET, F. M. (I945), 'Virus as Organism,' Cambridge, Mass., Harvard University Press.

CLAUDE, A. (1938), Proc. Soc. exp. Biol., N.Y., 39, 398.

CLAUDE, A., and PORTER, K. R. (1947), Cancer Res., 7, 421.

DARLINǴTỎN, C. D. (1944), Nature, 154, 164.

DARLINGTON, C. D. (1948), Brit. F. Cancer, $2,118$.

GESSLER, A. E., and GREY, C. E. (1947), Exp. Med. Surg., 5, 307. GROSS, L., GESSLER, A. E., and MCCARTY, K. S. (1950), Proc. Soc. exp. Biol., N.Y., 75, 270.

KIDD, J. G. (1946), Cold. Spr. Harb. Sym. quant. Biol.; II 94

NEEDHAM, J. (I942), 'Biochenistry and Morphogenesis,' Ist Ed., Cambridge, Cambridge University Press.

OBERLING, C. (r944), 'The Riddle of Cancer,' New Haven, Yale University Press.

PORTER, K. R., and THOMPSON, H. P. (1948), f. exp. Med.,

POTT, I5. (1775), ' Chirurgical Observations,' London, Hawes,

PULLINGER, B. D. (1949), Lancet, ii, 823.

YAMAGIWA, K., and ICHIKAWA, K. (1915), Mitt. med. Fak., Tokio, 15, 295 .

YAMAGIWA, K., and ICHIKAWA, K. (1918), Ұ. Cancer Research, 3, I. 


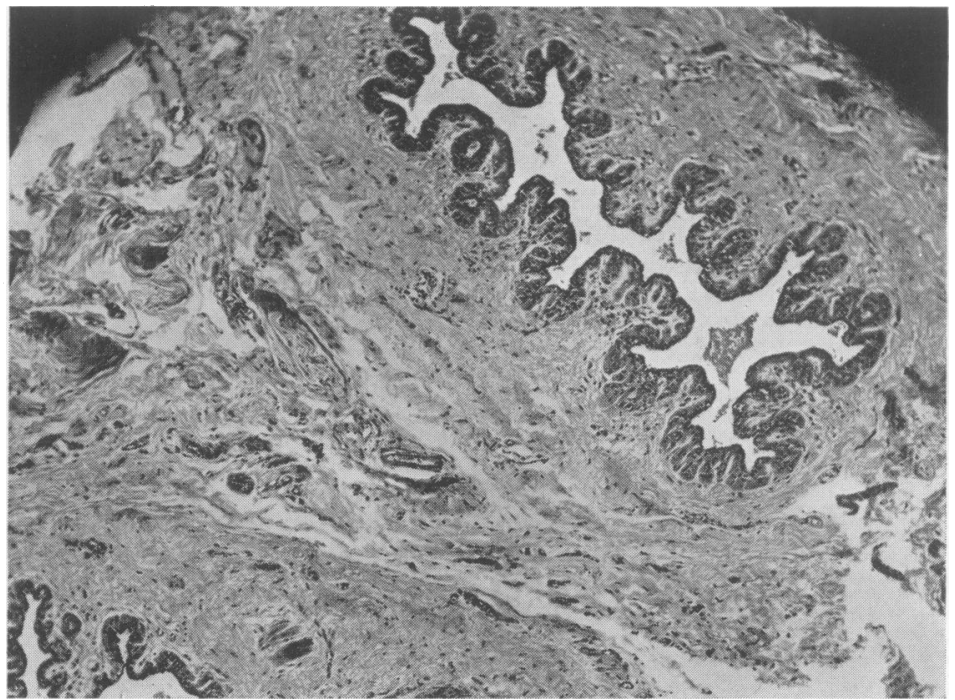

FIG. I.-Microscopic papillomatosis. Photomicrograph of a section through the breast $(x 60)$ showing a duct in which there is epithelial polyp formation of microscopic size.

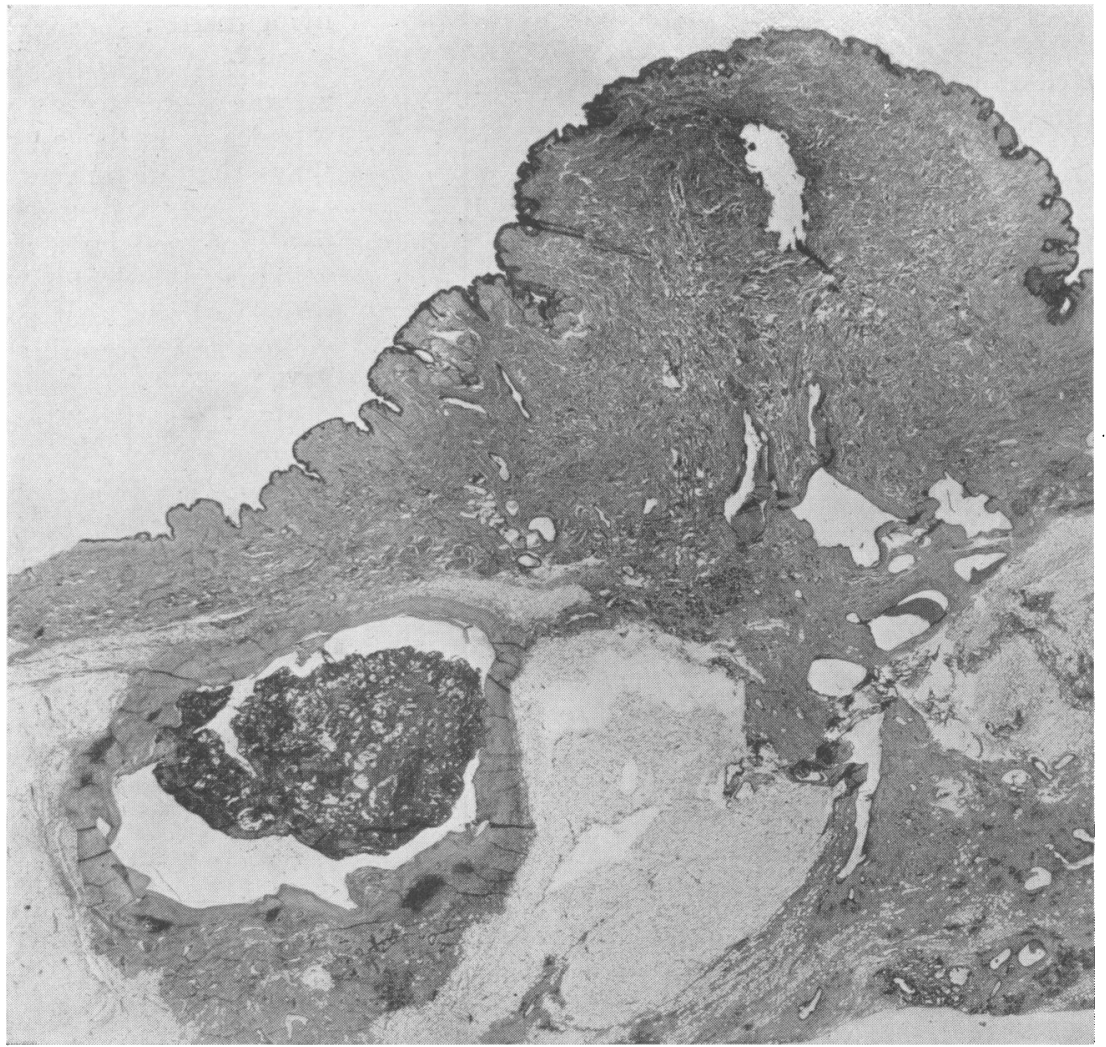

FIG. 2. - Solitary duct papilloma. Photomicrograph of a section through the nipple and underlying tissues ( $x$ 6) which shows a solitary duct papilloma suspended by a stalk from the wall of a cyst just below the areola. 


\section{ATLAS OF HISTOLOGIC DIAGNOSIS IN SURGICAL PATHOLOGY}

By K. T. Neubuerger, M.D. Pp. $x+460$, with 880 illustrations. London: Bailliere, Tindall and Cox. I95I. £4 4s.

This book is designed to augment the photomicrographic aspect of the standard surgical textbooks. It consists of 880 photomicrographs covering a great variety of pathological conditions, the text being restricted to short descriptions of the figures and brief notes on the clinical aspects.

The great majority of the illustrations are excellent photographs of good histological sections showing the relevant features of the particular conditions. A few of the photomicrographs are perhaps not up to the general standard, but in view of the tremendously wide field covered, this standard is exceptionally high.

Its high standard of illustration, together with the wide field of pathology covered will make this book invaluable to many surgeons and pathologists. The cost, moreover, is reasonable and compares very favourably with other recent publications of this nature.

\section{ANY QUESTIONS ?}

\section{From the 'British Medical Journal'}

First Series. Pp. xii +240 . London: B.M.A. 1951. 7s. 6d.

For several years a panel of experts have, each week, answered questions sent to the British Medical Fournal by medical men all over the world. This small book contains many of those questions and answers. The questions answered are varied and interesting. They not only cover ground on which the general practitioner treads every day, but often touch on subjects which, while only occurring infrequently, are rarely found in the text-books.

The replies have obviously been well considered and are excellent. True there are some with which a general practitioner may not agree entirely, but that only makes the book more readable.

On the flyleaf is a statement saying that this book is indispensable to the general practitioner. This is an opinion to which the reviewer cannot subscribe, but there is no doubt that no doctor, be he general practitioner or consultant, can read this book without interest and without adding considerably to his store of knowledge. G.M.W.

\section{ERRATUM}

\begin{tabular}{|c|c|c|c|c|}
\hline & & $\begin{array}{c}\text { NOT FILTERABLE NOT } \\
\text { DETECTED BY OTHER } \\
\text { MEANS }\end{array}$ & $\begin{array}{c}\text { NOT FILTERABLE BUT } \\
\text { DETECTED BY OTHER } \\
\text { MEANS }\end{array}$ & FILTERABLE \\
\hline $\begin{array}{l}P \\
\text { A } \\
R \\
\text { T } \\
\text { I } \\
C \\
\text { L } \\
\text { E } \\
S\end{array}$ & $\begin{array}{c}\text { CENES, } \\
\text { PLASMACENES, } \\
\text { OTHER NORMAL" } \\
\text { "CE LL } \\
\text { CONSTI TUENTS }\end{array}$ & $\begin{array}{l}\text { CELL PARTICLES } \\
\rightarrow \quad \text { RENDERED } \\
\text { ABNORMAL }\end{array}$ & $\begin{array}{c}\text { DETECTABLE } \\
\text { INTRACELLULAR } \\
\text { I PART ICLLS } \\
\text { PVIRUS-PROIOPLASM } \\
\text { COMPLEXES) }\end{array}$ & $\rightarrow \quad V I R \cup S E S$ \\
\hline \multirow{9}{*}{$\begin{array}{l}\text { N } \\
\text { E } \\
\text { O } \\
P \\
\text { L }\end{array}$} & \multirow{9}{*}{ FOETUS } & $\begin{array}{c}\text { MOST SPONTANEOUS } \\
\text { NEOPLASMS }\end{array}$ & & \multirow[b]{3}{*}{$\begin{aligned} & \text { SOME CHEMICALLY } \\
\rightarrow & \text { INDUCED TUMOURS } \\
& \text { (FILTERABLE) }\end{aligned}$} \\
\hline & & $\begin{array}{l}\text { MOST CHEMICALLY } \\
\text { INDUCED TUMOURS }\end{array}$ & & \\
\hline & & $\begin{array}{l}\text { SOME CHEMICALLY } \\
\text { INDUCED TUMOURS * } \\
\text { (NON-FI LTERABLE) }\end{array}$ & & \\
\hline & & & $\begin{array}{l}\text { NON-FILTERABLE } \\
\text { CHICKEN TUMOURS }\end{array}$ & \\
\hline & & & $\begin{array}{c}\text { ROUS SARCOMA } \\
\text { (NON-F ILTERABLE - } \\
\text { PHASE) }\end{array}$ & $\begin{array}{l}\rightarrow \text { ROUS SARCOMA } \\
\text { (FILTERABLE) }\end{array}$ \\
\hline & & SHOPE CARCINOMA & \#SHOPE CARCINOMA & —SHOPE PAPILLOMA \\
\hline & & & & $\begin{array}{l}\text { SHOPE CARCINOMA } \\
+\quad \text { IN } \\
\text { SUCKL INC RABB ITS }\end{array}$ \\
\hline & & & & $\begin{array}{l}\text { MILK-FACTOR } \\
\text { CARCINOMATA }\end{array}$ \\
\hline & & & & $\begin{array}{l}\text { FROC RENAL } \\
\text { CARCINOMATA }\end{array}$ \\
\hline & NORMAL & $A$ & $B \quad N O$ & \\
\hline
\end{tabular}

We much regret that the above table (Table I), referred to on pp. 25 and 26 of our January issue, was omitted from Dr. Warner's article. The Editor begs to offer his sincere apologies. 